\title{
Optimized Design of High Power Density EMI Filters for Power Electronic Converters
}

\author{
G. Ala, G. C. Giaconia, G. Giglia \\ Dipartimento dell'Energia, Ingegneria \\ dell'Informazione e Modelli Matematici \\ Università degli Studi di Palermo \\ Palermo, Italy
}

\author{
M. C. Di Piazza, M. Luna, G. Vitale \\ Istituto di Studi sui Sistemi Intelligenti \\ per l'Automazione (ISSIA) \\ Consiglio Nazionale delle Ricerche (CNR) \\ Palermo, Italy
}

\author{
P. Zanchetta \\ Department of Electrical and Electronic Engineering \\ University of Nottingham \\ Nottingham, United Kingdom
}

\begin{abstract}
Nowadays, power density of power converters and related EMI filters is gaining more and more attention. This severely impacts on the design constraints in several application domains. A conventional design of the EMI filter does not guarantee the selection of components/configuration leading to the best power density. For this reason, an optimized design procedure of discrete EMI filters in terms of power density is proposed in this paper. It is based on a previously developed rule-based design procedure, introducing here additional features to obtain a more effective optimization of EMI filter's power density. The proposed approach has been validated in terms of EMI filter's performance and size reduction, by a comparison between an EMI filter designed using the optimized procedure and a conventionally designed one, for two different case studies.
\end{abstract}

Keywords- EMI filter design, Power density, Power converters, Electrical Drives.

\section{INTRODUCTION}

Power electronic converters are used in a broad variety of industrial applications. In many of these (e.g., aeronautic, automotive, etc.) a very compact system is strongly required. Therefore, power density is becoming an increasingly stringent design constraint

The use of power devices with high speed commutation allows to reduce the size of the energy storage passive elements (i.e., inductors and capacitors). On the other hand, high-speed switching operation of power electronic converters usually causes relevant electromagnetic interference (EMI), potentially affecting other devices placed in their proximity. For this reason, EMI is one of the major issues in power electronic systems design, particularly when dealing with stringent standard limits [1]-[3].

The size of the EMI filter can contribute up to $30 \%$ of the total size and weight of the converter system. Therefore, a filter design matching the maximum power density is strongly desired, especially for the applications in which compactness and low weight are the primary constraints [4]-[7]. It is worth noting that, once the filter topology has been chosen and the values of its components (Common Mode/Differential Mode inductors/capacitors) have been defined, there is a huge amount of possibilities for practical configurations. Moreover, the identification of the configuration leading to the optimal power density is a challenging task. The conventional design of EMI filters requires a significant computational effort and it does not guarantee the optimal choice of filter components in order to obtain the maximum power density.

Therefore, in order to reduce the effort and the time needed for properly selecting the filter components, an automatic rulebased EMI filter design procedure that allows obtaining optimal power density has been previously proposed [8]. In this paper, the algorithm underlying the filter design procedure of [8] has been suitably improved and refined to obtain a more effective optimization of EMI filter's power density; on the other hand, easy implementation features and low computational demand have been maintained. Starting from the EMI noise to be attenuated, the proposed procedure allows a fast selection of EMI filter components, circuit configuration and number of stages, leading to the minimum overall filter size. The effectiveness of the proposed design approach has been validated using a suitably devised experimental setup and considering two different case studies.

\section{GENERAL StePS OF EMI FILTER DESIGN}

The generation and coupling mechanisms, as well as the Common Mode (CM) and Differential Mode (DM) EMI paths, are different; thus, separated filter sections are needed in order to obtain a suitable attenuation for EMC compliance. Therefore, the initial step of an effective EMI filter design is the separate evaluation of the two noise modes.

Firstly, it is necessary to identify the crucial point on the experimental curve of the EMI emission, generally the emission peak at the lowest frequency within the EMI range $(150 \mathrm{kHz}-30 \mathrm{MHz})$. 
The required attenuations $A t t_{\text {req_CM }}, A t t_{\text {req_DM }}$ for the CM and DM noise are expressed as:

$$
\begin{aligned}
& A t t_{\text {req_CM }}=A_{h_{-} C M}-\text { Limit }+S M \\
& A t t_{\text {req_DM }}=A_{h_{-} D M}-\text { Limit }+S M
\end{aligned}
$$

where $A_{h_{-} C M}, A_{h_{-} D M}$ are the amplitudes of the harmonic to be attenuated, Limit is the maximum amplitude allowed by the reference standard at the frequency of interest and $S M$ denotes an additional safety margin, usually set to $6 d B \mu V$.

The cutoff frequency of the CM or DM filter is then expressed by (3), where $f_{\text {att } h}$ is the harmonic frequency to be attenuated, Att filter is the filter inherent attenuation, which is related to the filter circuit configuration, and $n$ is the number of filter stages.

$$
f_{\bullet \_C M / D M}=\frac{f_{\text {att_h }}}{10^{\left(\frac{A t t_{\text {req }}}{n-A t t_{\text {fitter }}}\right)}}
$$

When both corner frequencies are known, the inductance and capacitance values of the $\mathrm{CM} / \mathrm{DM}$ sections of the EMI filter can be determined. The CM capacitance is constrained by standards to comply with safety issues (ground current), whereas DM parameters can be selected exploiting some degrees of freedom, considering that the value of the inductance $L_{D M}$ will be reduced if the value of the capacitance $C_{D M}$ is increased and vice-versa. For this reason, the DM section design can consider either the case of a $L_{D M}$ obtained by the leakage inductance of the CM choke $\left(L_{\text {leakrage }}=0.2 \div 2 \% L_{C M}\right.$, depending on the core material) or the case of a $L_{D M}$ realized by means of additional inductors [7], [8]. The equations that are used to determine the inductors and capacitors values are (4) and (5), respectively.

$$
\begin{aligned}
& L_{C M}=\frac{1}{C_{C M}\left(2 \pi f \cdot \bullet_{-C M}\right)^{2}}
\end{aligned}
$$

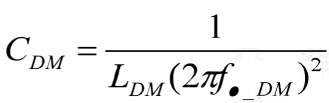

After determining the values of the CM and DM filter components, it is critical to choose the inductors' cores with suitable geometrical dimensions and magnetic properties so to prevent magnetic saturation, considering the maximum values of the CM/DM noise currents measured in time domain [9][20].

The conventional design of EMI filters requires a significant computational effort and it does not guarantee the optimal choice of filter components in order to obtain the maximum power density. For this reason, an optimized design procedure of discrete EMI filters in terms of power density is described in the following section.

\section{EMI FILTER OPTIMIZED DESIGN PROCEDURE}

The optimized design procedure presented in this paper is based on a rule-based algorithm previously developed by the same authors in [8] and suitably improved to obtain a more effective design. The design procedure starts from the basic steps illustrated in Section II and introduces the additional objective of pursuing the best power density for the EMI filter.

The optimized design procedure takes into account the main characteristics of the filter application: the power electronic circuits under study, the filter design constraints and some databases with parameters extracted by datasheets of commercial components for the realization of EMI filters. It repeats the steps of the conventional design procedure for different configurations (e.g., varying core material and model, number of stages, etc.) and chooses the configuration exhibiting the best power density. Since multi-stage filter can occupy a smaller volume than single stage one, depending on the components which are used, the optimized design procedure considers the possibility to span a number of filter stages ranging from 1 to 5 .

To avoid the degrading of the desired EMI filter performance, the algorithm verifies the fulfillment of the condition $B_{\text {max }}<B_{\text {sat }}$ for the considered magnetic materials (nano-crystalline or ferrite). Saturation of the magnetic core is verified in both the CM and DM section design procedures. Finally, the algorithm calculates the EMI filter volume and weight of all possible configurations and select the one with the best power density.

Fig. 1 shows a scheme that summarizes the overall concept of the optimized technique, where the used symbols stand for:

- $n_{\text {phase }}$ : number of AC phases/DC lines of the power electronic system;

- $V_{N}$ : nominal voltage of the power converter;

- $I_{\text {max_phase }}$ : maximum operating current;

- $I_{C M \_ \text {max }}, I_{D M \_ \text {max }}$ : maximum CM and DM currents;

- $E M I_{C M}, E M I_{D M}$ : measured CM and DM spectra;

- $n_{\text {stage }}$ : number of filter stages in range $1 \div 5$;

- $N_{C M}, N_{D M}$ : number of turns of CM and DM inductors;

- $N_{\max }$ : maximum number of turns for each core;

- $B_{\text {max }}, B_{\text {sat }}:$ maximum/saturation magnetic induction;

- $C_{y}, C_{x}$ : capacitance of phase-to-ground/phase-to-phase capacitors;

- $V_{C x, y_{-} \text {rated: }}$ capacitors' rated voltage;

- $k$ : multiplier factor (equal to 2.5 for DC systems and 4.2 for AC systems);

- $T, T_{\max }$ : operating/maximum temperature;

- $A W G$ : conductor diameter expressed in American Wire Gauge unit.

More details about the databases and the rule-based algorithm have been described in [8]. With respect to [8] additional features have been added to obtain a more effective design. In particular, besides the core database, the database of commercial $C_{x}$ and $C_{y}$ capacitors has been extended and a new database of conducting wires has been included. 




Fig. 1. Concept of the optimized technique.

In this way, the volume/weight contribution given by the inductor wires (non-negligible when dealing with rated power of hundreds of watts and beyond) is included in the EMI filter calculations. Furthermore, the CM capacitor can now be chosen either on the basis of SAE AES 1831 standard requirements [22] or by explicitly specifying the maximum ground leakage current.

The cores' dimensions have been chosen so as to design EMI filters for applications able to manage powers up to some $\mathrm{kW}$.

\section{THE CASE STUDIES}

The improved optimized EMI filter design procedure has been validated on two suitable experimental rigs. Moreover, the optimized EMI filter performance has been verified against both military and civilian technical standards.

The first case study (case study 1) consists on a PWM IGBT Voltage Source Inverter (VSI) that supplies a threephase induction motor with the following characteristics: rated voltage $U_{N}=48 \mathrm{~V}$, rated power $P_{N}=220 \mathrm{~W}$, maximum current $I_{\max }=5 \mathrm{~A}$. The VSI is based on a STGIPS10K60A power module and on an Altera Cyclone III FPGA board implementing the PW M modulator.

The VSI switching frequency is equal to $20 \mathrm{kHz}$ and the output voltage is $48 \mathrm{~V}$. This is a typical case of induction motor drive supplied by a DC power grid; it is very common, for example, either in vehicle applications (road vehicles, marine vehicles, aircrafts), as well as in some residential/commercial smart buildings [25],[26].

In the second case study (case study 2), the device under study (DUT) is a DC motor drive with rated voltage of $12 \mathrm{~V}$. It is composed of a voltage regulator based on a DC/DC boost converter and a DC motor with a rated power of $30 \mathrm{~W}$.

The boost converter is based on the following devices: MURB820: Ultrafast Rectifier, IRFP150N: Power MOSFET, Inductor $320 \mu \mathrm{H}$, output capacitance $220 \mu \mathrm{F}$, switching frequency $20 \mathrm{kHz}$. This is a typical application for automotive environment in which the presence of low-power loads supplied with different voltage levels requires the use of DC/DC converters [27].

Fig. 2 shows a scheme of the experimental arrangement for the two case studies.

A dual DC Line Impedance Stabilization Network (LISN) with a voltage capability up to $600 \mathrm{~V}$ has been set-up and used to measure the conducted EMI [21]. The experimental rigs have been equipped with a R\&S FSH4 $(100 \mathrm{kHz}-3.6 \mathrm{GHz})$ spectrum analyzer and a RF current probe R\&S EZ-17 for measurements in the frequency range $20 \mathrm{~Hz}-100 \mathrm{MHz}$ with a maximum DC current of $300 \mathrm{~A}$. 


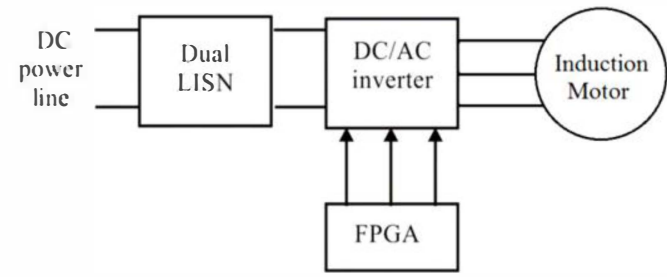

(a)

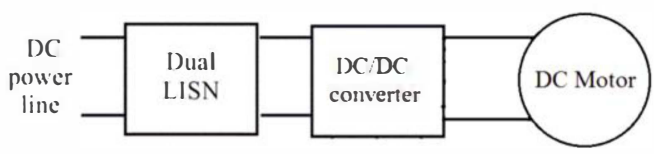

(b)

Fig. 2. Scheme of the experimental rigs: (a) case study 1; (b) case study 2 .

\section{EXPERIMENTAL VALIDATION AND DISCUSSION}

Measured conducted disturbances have been compared with the limits reported in CISPR 25 [23] and MIL-STD-461G [24] standards to verify the compliance with both civilian and military standards. As for CISPR 25 standard, it deals with limits and methods of measurement of radio disturbance for the protection of receivers used on vehicles. Its limits are referred to five different classes, in rising order of required reduction of the maximum electromagnetic disturbance level that the devices can produce on board. Two CISPR 25 limit curves are reported in Figs. 3 and 4: the Class 5 limit, which is the most stringent, and the Class 4 limit.

In particular, the emission of case study 1 has been compared with the limits of both standards, i.e., CISPR 25 and MIL-STD-461G; on the other hand, only the CISPR 25 has been considered for case study 2 , since it is the only one that can be applied for the given DUT.

As shown in Figs. 3 and 4, the emission profiles in both the considered case studies exceed the limits of the standard that has been chosen as a reference. This calls for a suitable input EMI filtering.

On the basis of the conventional and optimized design procedures described in sections II and III, EMI filters have been set up and the following required attenuations have been used for the design procedures:

- Case study 1:

$\mathrm{Att}_{\text {req_CM }}=30 \mathrm{~dB} \mu \mathrm{V} @ 150 \mathrm{kHz}$;

$\mathrm{Att}_{\text {req_DM }}=60 \mathrm{~dB} \mu \mathrm{V} @ 170 \mathrm{kHz}$.

- Case study 2:

$$
\begin{aligned}
& \mathrm{Att}_{\text {req_CM }}=16.8 \mathrm{~dB} \mu \mathrm{V} @ 150 \mathrm{kHz} \\
& \mathrm{Att}_{\text {req_DM }}=45.9 \mathrm{~dB} \mu \mathrm{V} @ 150 \mathrm{kHz} .
\end{aligned}
$$

Futhermore, the input data shown in Tables I and II have been used to run the optimized design algorithm. It is worth noting that SAE AS 1831 standard has been used for $\mathrm{C}_{\mathrm{y}}$ selection in case study 1 ; on the contrary, the maximum ground leakage current has been considered in case study 2 .
For both case studies, the conventional design procedure led to a single stage configuration, whereas the optimized procedure selected a double stage configuration. A comparison of the optimized filters with the conventionally designed ones has been carried out verifying their size and performance. Tables III and IV summarize the results.

Evaluating the volume and weight of the two filters, it is possible to observe that the optimized design leads to a reduction in volume and weight in both case studies. In particular, a reduction of $44 \%$ in volume and of $53 \%$ in weight is obtained in case study 1 . On the other hand, a reduction of $38 \%$ in volume and of $41 \%$ in weight is obtained in case study 2.

TABLE I. INPUT DATA FOR CASE STUDY 1.

\begin{tabular}{|l|l|}
\hline Filter topology & $\Gamma-\Pi$ \\
\hline Reference standard & Military Standard 461F/CISPR25 Class 5 \\
\hline System type & DC system \\
\hline $\mathrm{U}_{\mathrm{N}}$ & $48 \mathrm{~V}$ \\
\hline $\mathrm{I}_{\max }$ & $5 \mathrm{~A}$ \\
\hline $\mathrm{I}_{\mathrm{cm} \max }$ & $32 \mathrm{~mA}$ \\
\hline $\mathrm{I}_{\mathrm{dm} \max }$ & $150 \mathrm{~mA}$ \\
\hline $\mathrm{C}_{\mathrm{y}}$ & $100 \mathrm{nF}(\mathrm{SAE}$ AS 1831) \\
\hline
\end{tabular}

TABLE II. INPUT DATA FOR CASE STUDY 2.

\begin{tabular}{|l|l|}
\hline Filter topology & $\Gamma-\Pi$ \\
\hline Reference standard & CISPR25 Class 5 \\
\hline System type & DC system \\
\hline $\mathrm{U}_{\mathrm{N}}$ & $12 \mathrm{~V}$ \\
\hline $\mathrm{I}_{\max }$ & $2.5 \mathrm{~A}$ \\
\hline $\mathrm{I}_{\mathrm{cm} \max }$ & $30 \mathrm{~mA}$ \\
\hline $\mathrm{I}_{\mathrm{dm} \max }$ & $56.5 \mathrm{~mA}$ \\
\hline $\mathrm{C}_{\mathbf{y}}$ & $\begin{array}{l}102 \mathrm{nF} \text { (maximum ground leakage current } \\
=0.85 \mathrm{~mA})\end{array}$ \\
\hline
\end{tabular}

TABLE III. COMPARISON BETWEEN OPTIMIZED AND CONVENTIONALLY-

\begin{tabular}{|c|c|c|}
\hline & Conventional Project & Optimized Project \\
\hline Number of stages & 1 & 2 \\
\hline $\mathrm{L}_{\mathrm{CM}} @ 10 \mathrm{kHz}$ & $0.8 \mathrm{mH}$ & $80 \mu \mathrm{H}$ (each stage) \\
\hline $\begin{array}{l}\text { CM inductor core } \\
\text { dimensions } \\
(\mathrm{mm} \times \mathrm{mm} \times \\
\mathrm{mm})\end{array}$ & $27.9 \times 13.6 \times 12.5$ & $\begin{array}{l}14.3 \times 8.5 \times 7.0 \text { (each } \\
\text { stage) }\end{array}$ \\
\hline $\begin{array}{l}\mathrm{CM} \text { core } \\
\mathrm{A}_{\mathrm{L}} @ 10 \mathrm{kHz}\end{array}$ & $\begin{array}{l}65.5 \mu \mathrm{H} \\
\text { (Vitroperm 500F, model } \\
\text { T60006-L2025-W380) }\end{array}$ & $\begin{array}{l}10 \mu \mathrm{H} \\
\text { (Vitroperm 500F, } \\
\text { model T60006-L2012- } \\
\text { W498) (each stage) }\end{array}$ \\
\hline $\begin{array}{l}\text { Nunber of turns } \\
\text { per CM winding }\end{array}$ & 5 & 4 (each stage) \\
\hline $\mathrm{C}_{\mathrm{CM}}$ & $200 \mathrm{nF}$ & $100 \mathrm{nF}$ (each stage) \\
\hline $\mathrm{C}_{\mathrm{y}}$ & $\begin{array}{l}100 \mathrm{nF} \text {, ceramic, } 250 \mathrm{~V} \text {, } \\
\text { (Murata } \\
\text { RDER72E104K2) }\end{array}$ & $\begin{array}{l}47 \mathrm{nF} \text {, ceramic, } 250 \mathrm{~V} \text {, } \\
\text { (Murata } \\
\text { RDER72E473K2) } \\
\text { (each stage) }\end{array}$ \\
\hline $\mathrm{L}_{\mathrm{DM}} @ 10 \mathrm{kHz}$ & $\begin{array}{l}1.6 \mu \mathrm{H}\left(\mathrm{L}_{\text {leakage }}=0.2 \%\right. \\
\left.\mathrm{L}_{\mathrm{CM}}\right)\end{array}$ & $\begin{array}{l}160 \mathrm{nH}\left(\mathrm{L}_{\text {leakage }}=0.2 \%\right. \\
\left.\mathrm{L}_{\mathrm{CM}}\right)(\text { (each stage) }\end{array}$ \\
\hline $\mathrm{C}_{\mathrm{DM}}$ & $\begin{array}{l}47 \mu \mathrm{F} \text {, electrolytic, } \\
400 \mathrm{~V},(\text { Panasonic } \\
\text { EEUEE2G470) }\end{array}$ & $\begin{array}{l}47 \mu \mathrm{F} \text {, electrolytic, } \\
160 \mathrm{~V}, \text { (Panasonic } \\
\text { EEUEE2C470) } \\
\text { (each stage) }\end{array}$ \\
\hline Wire size & $15 \mathrm{AWG}$ & $15 \mathrm{AWG}$ \\
\hline Volume & $25.87 \mathrm{~cm}^{3}$ & $14.44 \mathrm{~cm}^{3}$ (all stages) \\
\hline Weight & $44 \mathrm{~g}$ & 20.66 g (all stages) \\
\hline
\end{tabular}
DESIGNED EMI FILTERS (CASE STUDY 1). 
TABLE IV. COMPARISON BETWEEN OPTIMIZED AND CONVENTIONALLYDESIGNED EMI FILTERS (CASE STUDY 2).

\begin{tabular}{|c|c|c|}
\hline & Conventional Project & Optimized Project \\
\hline Number of stages & 1 & 2 \\
\hline $\mathrm{L}_{\mathrm{CM}} @ 10 \mathrm{kHz}$ & $60 \mu \mathrm{H}$ & $51 \mu \mathrm{H}$ (each stage) \\
\hline $\begin{array}{l}\text { CM inductor core } \\
\text { dimensions } \\
(\mathrm{mm} \times \mathrm{mm} \times \\
\mathrm{mm})\end{array}$ & $19 \times 11 \times 8.0$ & $\begin{array}{l}11.2 \times 5.1 \times 5.8 \text { (each } \\
\text { stage) }\end{array}$ \\
\hline $\begin{array}{l}\mathrm{CM} \text { core } \\
\mathrm{A}_{\mathrm{L}} @ 10 \mathrm{kHz}\end{array}$ & $\begin{array}{l}30 \mu \mathrm{H} \\
\text { (Vitroperm 500F, model } \\
\text { T60006-L2017-W515) }\end{array}$ & $\begin{array}{l}25.5 \mu \mathrm{H} \\
\text { (Vitroperm 500F, } \\
\text { model T60006-L2009- } \\
\text { W914) (each stage) }\end{array}$ \\
\hline $\begin{array}{l}\text { Nunber of turns } \\
\text { per CM winding }\end{array}$ & 2 & 2 (each stage) \\
\hline $\mathrm{C}_{\mathrm{CM}}$ & $200 \mathrm{nF}$ & $100 \mathrm{nF}$ (each stage) \\
\hline $\mathrm{C}_{\mathrm{y}}$ & $\begin{array}{l}100 \mathrm{nF} \text {, ceramic, } 100 \mathrm{~V} \text {, } \\
\text { (Murata } \\
\text { RDER72A104K1) }\end{array}$ & $\begin{array}{l}47 \mathrm{nF} \text {, ceramic, } 100 \mathrm{~V} \text {, } \\
\text { (Murata } \\
\text { RDER72A473K1) } \\
\text { (each stage) }\end{array}$ \\
\hline $\mathrm{L}_{\mathrm{DM}} @ 10 \mathrm{kHz}$ & $\begin{array}{l}120 \mathrm{nH}\left(\mathrm{L}_{\text {leakage }}=0.2 \%\right. \\
\left.\mathrm{L}_{\mathrm{CM}}\right)\end{array}$ & $\begin{array}{l}102 \mathrm{nH}\left(\mathrm{L}_{\text {leakage }}=0.2 \%\right. \\
\left.\mathrm{L}_{\mathrm{CM}}\right)(\text { each stage })\end{array}$ \\
\hline $\mathrm{C}_{\mathrm{DM}}$ & $\begin{array}{l}330 \mu \mathrm{F} \text {, electrolytic, } \\
160 \mathrm{~V},(\text { Panasonic } \\
\text { EEUEE2C331) }\end{array}$ & $\begin{array}{l}68 \mu \mathrm{F} \text {, electrolytic, } \\
160 \mathrm{~V},(\text { (Panasonic } \\
\text { EEUEE2C680) (each } \\
\text { stage) }\end{array}$ \\
\hline Wire size & $18 \mathrm{AWG}$ & $18 \mathrm{AWG}$ \\
\hline Volume & $25.06 \mathrm{~cm}^{3}$ & $15.54 \mathrm{~cm}^{3}$ (all stages) \\
\hline Weight & $34.83 \mathrm{~g}$ & 20.52 g (all stages) \\
\hline
\end{tabular}

In order to visually perceive the difference between the two approaches, a picture of the optimized EMI filter compared to the conventionally designed one in the case study 1 is shown in Figure 3: the higher compactness of the optimized filter is evident.

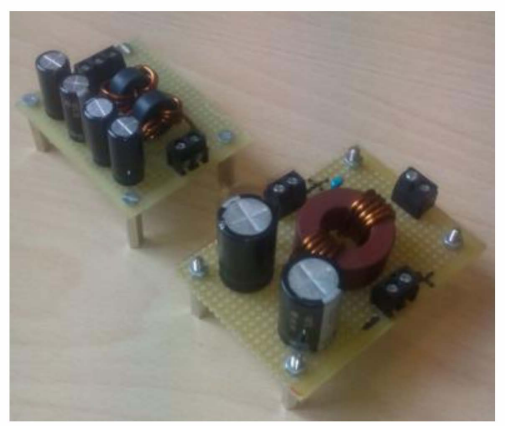

Fig. 3. Picture of conventionally designed EMI filter (on the right) and optimized EMI filter (on the left), in case study 1.

Morever, the EMI filters, designed according to the data of Tables III and IV, have been experimentally realized.

In order to evaluate the EMI filters mitigation performance, EMI measurements have been carried out in case study 1 and 2 without any filter, with the conventionally designed filter and with the optimized filter.

It is possible to observe in Figs. 4 and 5 that the optimized and the conventionally designed filters exhibit a satisfactory behavior. In particular in both case studies, with regard to CISPR 25, the filters allow to obtain a fully compliant behavior with the Class 4 limit and an acceptable behavior for the Class 5 limit.

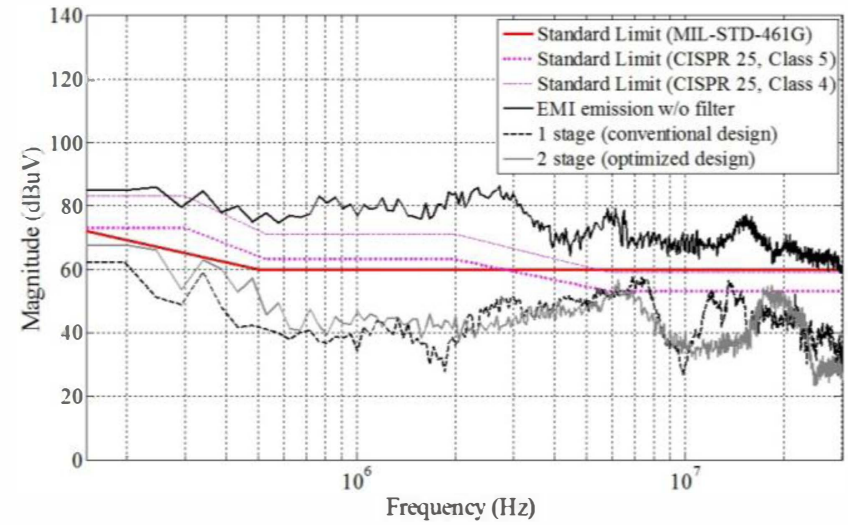

Fig. 4. Comparison of optimized and conventionally designed EMI filter performance (case study 1) - The start point of the frequency axis is $150 \mathrm{kHz}$.

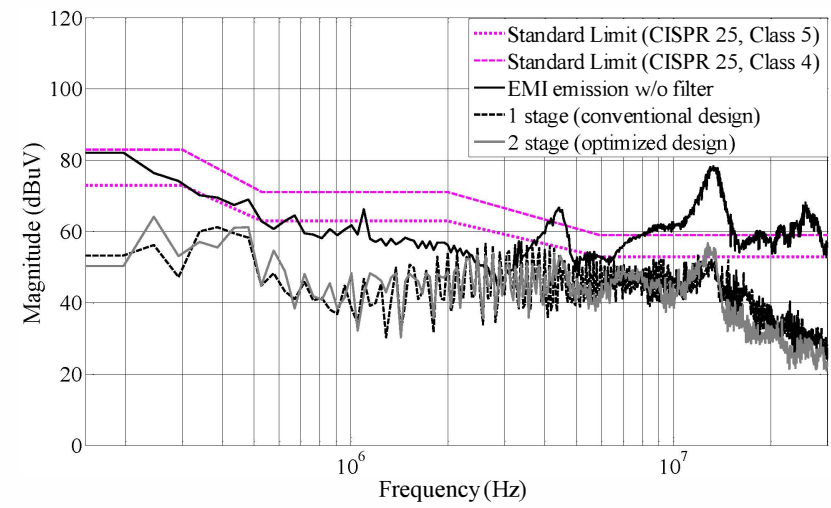

Fig. 5. Comparison of optimized and conventionally designed EMI filter performance (case study 2) - The start point of the frequency axis is $150 \mathrm{kHz}$.

Therefore, despite the higher compactness and power density achieved, the optimized EMI filter still allows to obtain the compliance of the power electronic systems under study with the reference standards.

\section{CONCLUSIONS}

This work deals with the power density issue in EMI filters used for mitigating EMI in power electronic systems. In detail, this paper proposes an improved rule-based optimized design procedure for the optimal and fast selection of discrete EMI filter components and configuration, aiming at obtaining the best power density. In order to validate the method, two case studies have been considered, devising suitable experimental test rigs. In particular, an inverter-fed induction motor drive and a DC motor drive supplied by a DC/DC boost converter have been used, respectively. The size and the performance of the EMI filters designed by the proposed procedure have been compared with those obtained by conventionally designed ones. The comparison, based on experimental tests, demonstrates the effectiveness of the proposed approach. In particular, a volume reduction of $44 \%$ and a weight reduction of $53 \%$ is obtained in the first case study and a reduction of $38 \%$ in volume and of $41 \%$ in weight is obtained in the second case study. 


\section{REFERENCES}

[1] G. L. Skibinski, R. J. Kerkman, D. W. Schlegel, "EMI Emissions of Modern PWM AC Drives”, IEEE Ind. Electron. Magaz., pp.47-81, Nov./Dec.1999.

[2] M. Silva, N. Hensgens, J. Oliver, P.Alou, "New considerations in the input filter design of a three-phase buck-type PWM rectifier for aircraft applications”, IEEE Energy Conv. Congr. Exp, pp. 4087 - 4092, 2011.

[3] M.C. Di Piazza, A Ragusa, G Vitale, "Power-loss evaluation in CM active EMI filters for bearing current suppression", IEEE Trans. Ind.Electron., vol. 58, pp. 5142-5153, Feb. 2011.

[4] J. W. Kolar, U. Drofenik, J. Biela, M. L. Heldwein, H. Ertl, T. Friedli and S. D. Round, "PWM Converter Power Density Barriers", Power Conversion Conference (PCC '07), Nagoya, 2007.

[5] G. Ala, M. C. Di Piazza, G. C. Giaconia, G. Giglia, G. Vitale, "Design and performance evaluation of a high power density EMI filter for PWM inverter-fed induction motor drives", IEEE 15th International Conf. on Environment and Electrical Engineering (EEEIC 2015), Rome, Italy, pp. 1573-1579, June 2015

[6] G. Ala, M. C. Di Piazza, G. C. Giaconia, G. Giglia, G. Vitale, "Design and performance evaluation of a high power density EMI filter for PWM inverter-fed induction motor drives", IEEE Trans. Industry Applicatons, vol. 52, pp. 2397-2404, 2016, DOI: 10.1109/TIA.2016.2518129.

[7] Y. Maillet, Rixin Lai, Shuo Wang, Fei Wang, R. Burgos, D. Boroyevich, "High-Density EMI Filter Design for DC-Fed Motor Drives", IEEE Trans. Power Electron., vol. 25, no. 5, May 2010.

[8] G. Ala, G. C. Giaconia, G. Giglia, M. C. Di Piazza, M. Luna, G. Vitale, P. Zanchetta, "Computer Aided Optimal Design of High Power Density EMI Filters", IEEE 16th International Conf. on Environment and Electrical Engineering (EEEIC 2016), 7-10 June 2016, Florence, Italy.

[9] E. Cardelli, "A general hysteresis operator for the modeling of vector fields," IEEE Trans. Magn. 47(8), 2056-2067 (2011).

[10] Ermanno Cardelli, Edward Della Torre, Antonio Faba, "A General Vector Hysteresis Operator: Extension to the 3-D Case", IEEE Transaction on Magnetics, Vol. 46, NO. 12, Pages: 3990-4000, December 2010.

[11] E. Cardelli, E. Della Torre, V. Esposito, A. Faba, "Theoretical Considerations of Magnetic Hysteresis and Transformer Inrush Current", IEEE Transaction on Magnetics, VOL. 45, NO. 11, Pages: 5247-5250, November 2009.

[12] E. Cardelli, A. Faba, R. Specogna, F. Trevisan, "Image Reconstruction of defects in Metallic Plates Using a Multi-Frequency Detector System and a Discrate Geometric Approach", IEEE Transactions On Magnetics, VOL. 43, NO. 4, Pages: 1857-1860, APRIL 2007.

[13] E. Cardelli, A. Faba, " A Benchmark Problem of Vector Magnetic Hysteresis for Numerical Models", IEEE Transactions on Magnetics, VOL. 50, NO. 2, February 2014.

[14] E. Cardelli, A. Faba, F. Tissi, "Surface field measurements in vector characterization of Si-Fe magnetic steel samples", International Journal of Applied Electromagnetics and Mechanics, Volume 44, Number 3-4, pages 331-338, April 2014.

[15] E. Cardelli, E. Della Torre, A. Faba, " Numerical Modeling of Hysteresis in Si-Fe Steels", IEEE Transactions on Magnetics, VOL. 50, NO. 2, February 2014.

[16] E. Cardelli, A. Faba, " Modeling of hysteresis in magnetic multidomains", Physica B: Condensed Matter, Vol. 435, p. 62-65, February 2014.

[17] S. Quondam Antonio, A. Faba, G. Carlotti, E. Cardelli, "Vector hysteresis model identification for iron-silicon thin films from micromagnetic simulations", Physica B: Condensed Matter, Volume 486, 1 April 2016, Pages 97-100.

[18] E. Cardelli, A. Faba, A. Laudani, S. Quondam Antonio, F. Riganti Fulginei, A. Salvini, "A moving approach for the Vector Hysteron Model", Physica B: Condensed Matter, Volume 486, 1 April 2016, Pages 92-96.

[19] E. Cardelli, A. Faba, "Modelling of vector hysteresis at macromagnetic scale: Open questions and challenges", Physica B: Condensed Matter, Volume 486, 1 April 2016, Pages 130-137.

[20] E. Cardelli, A. Faba, F. Tissi, "Prediction and Control of Transformer Inrush Currents", IEEE Transactions on Magnetics, VOL. 51, NO. 3, March 2015.

[21] M. C. Di Piazza, A. Ragusa, G. Vitale, "Common Mode EMI Propagation in High Voltage DC supplied Induction Motor Drives for Electric Vehicles Application", IEEE International Electric Machines and Drives Conference (IEMDC 2009), 3-6 May 2009.

[22] SAE AS 1831:1997 (R2010) Characteristics And Utilization Of Electrical Power, 270 V DC, Aircraft.

[23] "Vehicles, boats and internal combustion engines - Radio disturbance characteristics - Limits and methods of measurement for the protection of on-board receivers", CISPR 25, 2016.

[24] "Requirements for the control of electromagnetic interference characteristics of subsystems and equipment", Military Standard 461G, Dec. 2015.

[25] S. Anand, B. G. Fernandez, "Optimal voltage level for DC microgrids", in Proc. 36th Annual Conference on IEEE Industrial Electronics Society (IECON 2010), pp 3034-3039, 2010.

[26] H. Kakigano, N. Nomura, T. Ise, "Loss evaluation of DC distribution for residential houses compared with AC system", in Proc. of International Power Electronics Conference (IPEC), pp 480-486, 2010.

[27] S.Saponara, P. Tisserand, P. Chassard, D. My-Ton, "DC/DC Converter Integrated Architecture for $48 \mathrm{~V}$ Supplies in Micro/mild Hybrid Vehicle Electrical Engine Control Module", IEEE 16th International Conf. on Environment and Electrical Engineering (EEEIC 2016), 7-10 June 2016, Florence, Italy. 